Article

\title{
Generating Optimal Eighth Order Methods for Computing Multiple Roots
}

\author{
Deepak Kumar ${ }^{1, *}$, Sunil Kumar ${ }^{2}$, Janak Raj Sharma ${ }^{2}$ and Matteo d'Amore ${ }^{3, *}$ \\ 1 Department of Mathematics, Chandigarh University, Gharuan, Mohali 140413, India \\ 2 Department of Mathematics, Sant Longowal Institute of Engineering and Technology Longowal, \\ Sangrur 148106, India; sfageria1988@gmail.com or sunilkumar_pma1601@sliet.ac.in (S.K.); \\ jrshira@yahoo.co.in or jrsharma@sliet.ac.in (J.R.S.) \\ 3 Difarma, University of Salerno, Via Giovanni II, 132, 84084 Fisciano (SA), Italy \\ * Correspondence: deepak.babbi@gmail.com or deepak.e9086@cumail.in (D.K.); mdamore@unisa.it (M.d.)
}

Received: 6 November 2020; Accepted: 22 November 2020; Published: 25 November 2020

check for updates

\begin{abstract}
There are a few optimal eighth order methods in literature for computing multiple zeros of a nonlinear function. Therefore, in this work our main focus is on developing a new family of optimal eighth order iterative methods for multiple zeros. The applicability of proposed methods is demonstrated on some real life and academic problems that illustrate the efficient convergence behavior. It is shown that the newly developed schemes are able to compete with other methods in terms of numerical error, convergence and computational time. Stability is also demonstrated by means of a pictorial tool, namely, basins of attraction that have the fractal-like shapes along the borders through which basins are symmetric.
\end{abstract}

Keywords: nonlinear equations; Newton method; multiple roots; optimal convergence

MSC: 65H05; 41A25; 49M15

\section{Introduction}

Finding out the roots of nonlinear equations is an important task in numerical mathematics and has many advantages in engineering and applied sciences [1-5]. In the present work, we consider numerical methods for locating the multiple root $\alpha$ of multiplicity $m$ of a nonlinear equation $f(x)=0$. Mathematically, by multiple root $\alpha$ of multiplicity $m$, we mean that $f^{(j)}(\alpha)=0, j=0,1,2, \ldots, m-1$ and $f^{(m)}(\alpha) \neq 0$.

Based on the quadratically convergent modified Newton's method (see [6])

$$
x_{n+1}=x_{n}-m \frac{f\left(x_{n}\right)}{f^{\prime}\left(x_{n}\right)}, n=0,1,2, \ldots,
$$

many higher order methods have been developed in literature. For example, see [7-18] and references shown therein. According to Traub's terminology (see [5]), the Newton's method (1) is a one-point optimal order method. In recent years, a number of two-point optimal fourth order methods have been proposed for multiple zeros (see [10-12,14-16,19-25]). Some non-optimal multipoint methods of sixth order are developed in $[17,26]$. More recently, multipoint methods with optimal eighth order convergence have also been proposed in the literature which are shown below: 
Behl et al. [27] derived a three-point family of optimal method with eighth-order convergence, which is given by

$$
\begin{aligned}
& y_{n}=x_{n}-m \frac{f\left(x_{n}\right)}{f^{\prime}\left(x_{n}\right)} \\
& z_{n}=x_{n}-u_{n} Q\left(u_{n}\right) \frac{f\left(x_{n}\right)}{f^{\prime}\left(x_{n}\right)}, \\
& x_{n+1}=z_{n}-u_{n} t_{n} G\left(h_{n}, t_{n}\right) \frac{f\left(x_{n}\right)}{f^{\prime}\left(x_{n}\right)},
\end{aligned}
$$

where $u_{n}=\left(\frac{f\left(y_{n}\right)}{f\left(x_{n}\right)}\right)^{\frac{1}{m}}, h_{n}=\frac{u_{n}}{a_{1}+a_{2} u_{n}}$ and $t_{n}=\left(\frac{f\left(z_{n}\right)}{f\left(y_{n}\right)}\right)^{\frac{1}{m}}$, being $a_{1}$ and $a_{2}$ complex non-zero free parameters, $Q: \mathbb{C} \rightarrow \mathbb{C}$ and $Q: \mathbb{C}^{2} \rightarrow \mathbb{C}$ is a holomorphic function in the neighborhood of origin (0) and $(0,0)$.

Zafar et al. [28] proposed an optimal iterative scheme with eighth-order convergence, which is given as follows:

$$
\begin{aligned}
& y_{n}=x_{n}-m \frac{f\left(x_{n}\right)}{f^{\prime}\left(x_{n}\right)} \\
& z_{n}=x_{n}-m u_{n} H\left(u_{n}\right) \frac{f\left(x_{n}\right)}{f^{\prime}\left(x_{n}\right)}, \\
& x_{n+1}=z_{n}-u_{n} t_{n}\left(B_{1}+B_{2} u_{n}\right) P\left(t_{n}\right) G\left(w_{n}\right) \frac{f\left(x_{n}\right)}{f^{\prime}\left(x_{n}\right)},
\end{aligned}
$$

where $B_{1}, B_{2} \in R$ are free parameters and the weight functions $H: \mathbb{C} \rightarrow \mathbb{C}, P: \mathbb{C} \rightarrow \mathbb{C}$ and $G: \mathbb{C} \rightarrow \mathbb{C}$ are analytic functions in the neighborhood of origin (0) with $u_{n}=\left(\frac{f\left(y_{n}\right)}{f\left(x_{n}\right)}\right)^{\frac{1}{m}}, t_{n}=\left(\frac{f\left(z_{n}\right)}{f\left(y_{n}\right)}\right)^{\frac{1}{m}}$ and $w_{n}=\left(\frac{f\left(z_{n}\right)}{f\left(x_{n}\right)}\right)^{\frac{1}{m}}$

Geum et al. [29] have derived an optimal iterative scheme with eighth order convergence with weight function approach as follows:

$$
\begin{aligned}
& y_{n}=x_{n}-m \frac{f\left(x_{n}\right)}{f^{\prime}\left(x_{n}\right)} \\
& w_{n}=x_{n}-m L_{f}(s) \frac{f\left(x_{n}\right)}{f^{\prime}\left(x_{n}\right)}, \\
& x_{n+1}=x_{n}-m\left(L_{f}(s)+K_{f}(s, u)\right) \frac{f\left(x_{n}\right)}{f^{\prime}\left(x_{n}\right)},
\end{aligned}
$$

where weight functions $L_{f}: \mathbb{C} \rightarrow \mathbb{C}$ and $K_{f}: \mathbb{C}^{2} \rightarrow \mathbb{C}$ are holomorphic functions in the neighborhood of origin $(0)$ and $(0,0)$ with $s=\left(\frac{f\left(y_{n}\right)}{f\left(x_{n}\right)}\right)^{\frac{1}{m}}$ and $u=\left(\frac{f\left(w_{n}\right)}{f\left(y_{n}\right)}\right)^{\frac{1}{m}}$.

Behl et al. [30] also developed another three-point optimal iterative scheme with eighth order convergence involving free parameters for multiple zeros using a weight function approach as follows:

$$
\begin{aligned}
& y_{n}=x_{n}-m \frac{f\left(x_{n}\right)}{f^{\prime}\left(x_{n}\right)} \\
& w_{n}=y_{n}-m u \frac{f\left(x_{n}\right)}{f^{\prime}\left(x_{n}\right)} \frac{1+\beta u}{1+(\beta-2) u}, \quad \beta \in R \\
& x_{n+1}=z_{n}-u v \frac{f\left(x_{n}\right)}{f^{\prime}\left(x_{n}\right)}\left(\alpha_{1}+\left(1+\alpha_{2} v\right) P_{f}(u)\right),
\end{aligned}
$$


where $\alpha_{1}, \alpha_{2} \in \mathbb{R}$ are free parameters and the weight function $P_{f}: \mathbb{C} \rightarrow \mathbb{C}$ is an analytic function in the neighborhood of origin $(0)$ with $u=\left(\frac{f\left(y_{n}\right)}{f\left(x_{n}\right)}\right)^{\frac{1}{m}}$ and $v=\left(\frac{f\left(w_{n}\right)}{f\left(y_{n}\right)}\right)^{\frac{1}{m}}$.

Behl et al. [31] proposed yet another three-point optimal iterative scheme with eighth-order convergence involving free parameters for multiple zeros which is as follows:

$$
\begin{aligned}
& y_{n}=x_{n}-m \frac{f\left(x_{n}\right)}{f^{\prime}\left(x_{n}\right)} \\
& w_{n}=y_{n}-m u_{n} G_{f}\left(u_{n}\right) \frac{f\left(x_{n}\right)}{f^{\prime}\left(x_{n}\right)}, \\
& x_{n+1}=z_{n}+\frac{u_{n} w_{n}}{1-w_{n}} \frac{f\left(x_{n}\right)}{f^{\prime}\left(x_{n}\right)}\left(H_{f}\left(u_{n}\right)+K_{f}\left(v_{n}\right)\right),
\end{aligned}
$$

where weight function $G_{f}, H_{f}, K_{f}: \mathbb{C} \rightarrow \mathbb{C}$ is a holomorphic function in the neighborhood of origin (0) with $u_{n}=\left(\frac{f\left(y_{n}\right)}{f\left(x_{n}\right)}\right)^{\frac{1}{m}}, v_{n}=\left(\frac{f\left(z_{n}\right)}{f\left(x_{n}\right)}\right)^{\frac{1}{m}}$ and $v_{n}=\left(\frac{f\left(z_{n}\right)}{f\left(y_{n}\right)}\right)^{\frac{1}{m}}$.

Zafar et al. in [32] also developed a three-point optimal iterative scheme with eighth order convergence involving free parameters as follows:

$$
\begin{aligned}
& y_{n}=x_{n}-m \frac{f\left(x_{n}\right)}{f^{\prime}\left(x_{n}\right)} \\
& w_{n}=y_{n}-m u_{n} G_{f}\left(u_{n}\right) \frac{f\left(x_{n}\right)}{f^{\prime}\left(x_{n}\right)}, \\
& x_{n+1}=z_{n}-m u_{n} H\left(u_{n}, t_{n}, w_{n}\right) \frac{f\left(x_{n}\right)}{f^{\prime}\left(x_{n}\right)},
\end{aligned}
$$

where weight functions $G: \mathbb{C} \rightarrow \mathbb{C}$ and $H: \mathbb{C}^{3} \rightarrow \mathbb{C}$ are holomorphic functions in the neighborhood of origin $(0)$ and $(0,0,0)$ with $u_{n}=\left(\frac{f\left(y_{n}\right)}{f\left(x_{n}\right)}\right)^{\frac{1}{m}}, t_{n}=\left(\frac{f\left(z_{n}\right)}{f\left(y_{n}\right)}\right)^{\frac{1}{m}}$ and $w_{n}=\left(\frac{f\left(z_{n}\right)}{f\left(x_{n}\right)}\right)^{\frac{1}{m}}$.

We are motivated by the research moving in the direction of developing optimal higher order methods. So, we attempt to propose a new class of iterative methods with optimal eighth order for computing multiple zeros. The methodology is based on weight function approach for the construction of a new scheme. Each member of the proposed scheme has optimal order in the sense of the classical Kung-Traub conjecture [5]. The efficiency and robustness of the proposed methods are demonstrated by performing several numerical problems. We observe that our methods have better results than those obtained by the existing methods.

The rest of the paper is summarized as follows. In Section 2, the scheme of eighth order method is developed and its convergence is studied. Some special cases of the family are explored in Section 3. Numerical experiments for several examples are performed in Section 4 to demonstrate the applicability and efficiency of the presented methods. Section 5 contains complex geometry based on the geometrical tool basins of attraction. Concluding remarks are given in Section 6 .

\section{Construction of the Method}

This section contains the construction and convergence analysis of the proposed method with the main theorem. So, we consider the following three-step scheme whose first step is modified Newton iteration (1) for the known multiplicity $m \geq 1$ :

$$
x_{n+1}=\left\{\begin{array}{l}
y_{n}=x_{n}-m \frac{f\left(x_{n}\right)}{f^{\prime}\left(x_{n}\right)}, \\
z_{n}=y_{n}-m u\left(1+2 u-u^{2}\right) \frac{f\left(x_{n}\right)}{f^{\prime}\left(x_{n}\right)^{\prime}} \\
x_{n+1}=z_{n}-m(1+u) v H(v) \frac{f\left(x_{n}\right)}{f^{\prime}\left(x_{n}\right)}-m(u+w) v G(u) \frac{f\left(x_{n}\right)}{f^{\prime}\left(x_{n}\right)},
\end{array}\right.
$$


where $u=\left(\frac{f\left(y_{n}\right)}{f\left(x_{n}\right)}\right)^{\frac{1}{m}}, v=\left(\frac{f\left(z_{n}\right)}{f\left(x_{n}\right)}\right)^{\frac{1}{m}}, w=\left(\frac{f\left(z_{n}\right)}{f\left(y_{n}\right)}\right)^{\frac{1}{m}}$ and the functions $H: \mathbb{C} \rightarrow \mathbb{C}$ and $G: \mathbb{C} \rightarrow \mathbb{C}$ are analytic in the neighborhood of ' 0 '.

In order to discuss the convergence analysis of iterative scheme, (8) the following theorem is proved:

Theorem 1. Let $f: \mathbb{C} \rightarrow \mathbb{C}$ be an analytic function in a domain containing a multiple zero (say, $\alpha$ ) having multiplicity $m$. Assume that starter $x_{0}$ is close enough to $\alpha$, then the iteration scheme expressed by (8) possesses eighth order of convergence, when the following conditions are satisfied

$$
\left\{\begin{array}{l}
G(0)=1, G^{\prime}(0)=0, \text { and } G^{\prime \prime}(0)=-12, \\
H(0)=1, \text { and } H^{\prime}(0)=4
\end{array}\right.
$$

Proof. Let $e_{n}=x_{n}-\alpha$ be the error at $n$-th stage. Expanding $f\left(x_{n}\right)$ about $\alpha$ by Taylor's expansion, we have that

$$
\begin{aligned}
f\left(x_{n}\right)=\frac{f^{(m)}(\alpha)}{m !} e_{n}^{m}(1 & +C_{1} e_{n}+C_{2} e_{n}^{2}+C_{3} e_{n}^{3}+C_{4} e_{n}^{4}+C_{5} e_{n}^{5}+C_{6} e_{n}^{6}+C_{7} e_{n}^{7} \\
& \left.+C_{8} e_{n}^{8}+O\left(e_{n}^{9}\right)\right)
\end{aligned}
$$

and

$$
\begin{aligned}
f^{\prime}\left(x_{n}\right)= & \frac{f^{(m)}(\alpha)}{m !} e_{n}^{m-1}\left(m+C_{1}(m+1) e_{n}+C_{2}(m+2) e_{n}^{2}+C_{3}(m+3) e_{n}^{3}+C_{4}(m+4) e_{n}^{4}\right. \\
& \left.+C_{5}(m+5) e_{n}^{5}+C_{6}(m+6) e_{n}^{6}+C_{7}(m+7) e_{n}^{7}+C_{8}(m+8) e_{n}^{8}+O\left(e_{n}^{9}\right)\right)
\end{aligned}
$$

where $C_{k}=\frac{m !}{(m+k) !} \frac{f^{(m+k)}(\alpha)}{f^{(m)}(\alpha)}$ for $k \in \mathbb{N}$.

By using (9) and (10), we obtain that

$$
y_{n}-\alpha=\frac{C_{1}}{m} e_{n}^{2}+\sum_{i=1}^{6} \omega_{i} e_{n}^{i+2}+O\left(e_{n}^{9}\right),
$$

where $\omega_{i}=\omega_{i}\left(m, C_{1}, C_{2}, \ldots, C_{8}\right)$ are given in terms of $m, C_{1}, C_{2} \ldots C_{8}$ with explicitly written two coefficients $\omega_{1}=\frac{2 m C_{2}-(m+1) C_{1}^{2}}{m^{2}}, \omega_{2}=\frac{1}{m^{3}}\left\{3 m^{2} C_{3}+(m+1)^{2} C_{1}^{3}-m(4+3 m) C_{1} C_{2}\right.$, etc.

Developing $f\left(y_{n}\right)$ about $\alpha$,

$$
\begin{aligned}
f\left(y_{n}\right)= & \frac{f^{(m)}(\alpha)}{m !}\left(\frac{C_{2}}{m}\right)^{m} e_{n}^{2 m}\left(1+\frac{2 C_{2} m-C_{1}^{2}(m+1)}{C_{1}} e_{n}+\frac{1}{2 m c_{1}^{2}}\left\{\left(3+3 m+3 m^{2}+m^{3}\right) C_{1}^{4}\right.\right. \\
& \left.\left.2 m\left(2+3 m+2 m^{2}\right) C_{1}^{2} C_{2}+4(-1+m) m^{2} C_{2}^{2}+6 m^{2} C_{1} C_{3}\right\} e_{n}^{2}+\sum_{i=0}^{4} \bar{\omega}_{i} e_{n}^{i+4}+O\left(e_{n}^{9}\right)\right) .
\end{aligned}
$$

By using (9) and (12), we get expression of $u$ as

$$
u=\frac{C_{1}}{m} e_{n}+\frac{2 C_{2} m-C_{1}^{2}(m+2)}{m^{2}} e_{n}^{2}+\sum_{i=0}^{3} \eta_{i} e_{n}^{i+3}+O\left(e_{n}^{7}\right),
$$

where $\eta_{i}=\eta_{i}\left(m, C_{1}, C_{2}, \ldots, C_{8}\right)$ are given in terms of $m, C_{1}, C_{2}, \ldots, C_{8}$ with explicitly written one coefficient $\eta_{1}=\frac{1}{2 m^{3}}\left\{C_{1}^{3}\left(2 m^{2}+7 m+7\right)+6 C_{3} m^{2}-2 C_{2} C_{1} m(3 m+7)\right\}$ etc.

Inserting the expressions (9), (10) and (13) in the second step of scheme (8), we obtain that

$$
z_{n}-\alpha=\frac{(11+m) C_{1}^{3}-2 m C_{2} C_{3}}{2 m^{3}} e_{n}^{4}+\sum_{j=1}^{4} P_{j} e_{n}^{j+4}+O\left(e_{n}^{9}\right),
$$


where $P_{j}=P_{j}\left(m, C_{1}, C_{2}, \ldots, C_{8}\right)$ and $j=1,2,3,4$.

Expansion of $f\left(z_{n}\right)$ about $\alpha$ leads us to the expression

$$
f\left(z_{n}\right)=\frac{f^{(m)}(\alpha)}{m !} z_{n}^{m}\left(1+C_{1} z_{n}+C_{2} z_{n}^{2}+O\left(z_{n}^{3}\right)\right) .
$$

Using (9), (12) and (15), we get expressions of $v$ and $w$

$$
v=\frac{(11+m) C_{1}^{3}-2 m C_{2} C_{3}}{2 m^{3}} e_{n}^{3}+\sum_{j=0}^{3} Q_{j} e_{n}^{j+4}+O\left(e_{n}^{8}\right),
$$

where $Q_{j}=Q_{j}\left(m, C_{1}, C_{2}, \ldots, C_{7}\right), 1 \leq j \leq 4$

and

$$
w=\frac{(11+m) C_{1}^{2}-2 m C_{2}}{2 m^{3}} e_{n}^{2}+\sum_{i=0}^{4} R_{j} e_{n}^{j+3}+O\left(e_{n}^{8}\right)
$$

where $R_{j}=R_{j}\left(m, C_{1}, C_{2}, \ldots, C_{7}\right)$ are given in terms of $m, C_{1}, C_{2} \ldots C_{7}$.

Expansions of weight functions $G(u)$ and $H(v)$ in the neighborhood of origin ' 0 ' by Taylor series yield

$$
G(u) \approx G(0)+u G^{\prime}(0)+\frac{1}{2} u^{2} G^{\prime \prime}(0)
$$

and

$$
H(v) \approx H(0)+v H^{\prime}(0)+\frac{1}{2} v^{2} H^{\prime \prime}(0) .
$$

Hence by substituting (9), (10), (13), (16), (18) and (19) into the last step of scheme (8), we obtain the error equation

$$
e_{n+1}=\frac{(-1+H(0)) C_{1}\left(2 m C_{1}-(11+m) C_{1}^{2}\right)}{2 m^{3}} e_{n}^{4}+\sum_{i=1}^{4} \Gamma_{i} e_{n}^{i+4}+O\left(e_{n}^{9}\right),
$$

where $\Gamma_{i}=\Gamma_{i}\left(m, H(0), C_{1}, C_{2}, \ldots, C_{7}\right)$ are given in terms of $m, H(0), C_{1}, C_{2} \ldots C_{7}$ with $i=1,2,3$.

From Equation (20), it is clear that we will obtain at least fifth order convergence when $H(0)=1$. Using the value $H(0)=1$ in $\Gamma_{1}=0$, we will obtain

$$
G(0)=1
$$

By inserting the expression $H(0)=1$ and $G(0)=1$ in $\Gamma_{2}=0$, we have

$$
G^{\prime}(0)=0
$$

Now, with the help of the above independent expressions $H(0)=1, G(0)=1$ and $G^{\prime}(0)=0$ in $\Gamma_{3}=0$, we ascertain that

$$
H^{\prime}(0)=4
$$

Substituting $H(0)=1,(21)$, (22) and (23) in Equation (20), the error equation showing eighth order convergence is given by 


$$
\begin{aligned}
e_{n+1}= & \frac{1}{720 m^{7}}\left(\left(655751+990429 m+809345 m^{2}+335415 m^{3}+61304 m^{4}+2556 m^{5}\right) C_{1}^{7}-6 m(330143\right. \\
& \left.+491815 m+278255 m^{2}+61385 m^{3}+2882 m^{4}\right) C_{1}^{5} C_{2}+30 m^{2}\left(28649+29546 m+8971 m^{2}\right. \\
& \left.+514 m^{3}\right) C_{1} C_{3}+60 m^{2} C_{1}^{3}\left(\left(34857+35162 m+10263 m^{2}+562 m^{3}\right) C_{2}^{2}-2 m(2375+1320 m\right. \\
& \left.\left.+103 m^{2}\right) C_{4}\right)-360 m^{3} C_{1}^{2}\left(\left(3341+1740 m+127 m^{2}\right) C_{2} C_{3}-m(167+23 m) C_{5}\right)+360 m^{4} \\
& \times\left((417+43 m) C_{2}^{3} C_{3}-34 m C_{3} C_{4}-26 m C_{2} C_{5}\right)-120 m^{3} C_{1}\left(\left(4247+2070 m+139 m^{2}\right) C_{2}^{3}\right. \\
& \left.\left.-6 m(273+35 m) C_{2} C_{4}-3 m\left((305+39 m) C_{3}^{2}-10 m C_{6}\right)\right)\right) e_{n}^{8}+O\left(e_{n}^{9}\right) .
\end{aligned}
$$

Thus, proof of theorem is established.

\section{Some Special Cases of Weight Functions of G(u) and H(v)}

We explore some special cases of our proposed method (8) by employing different forms of weight functions. In this regard, the following simple members of the proposed family are defined:

Case 1. Let us describe the following weight functions satisfying the conditions established in Theorem 1:

$$
G(u)=\frac{1+6 u}{1+6 u+6 u^{2}} \text { and } H(v)=1+4 v .
$$

Then corresponding optimal eighth order iterative scheme is given by

$$
\left\{\begin{array}{l}
y_{n}=x_{n}-m \frac{f\left(x_{n}\right)}{f^{\prime}\left(x_{n}\right)} \\
z_{n}=y_{n}-m u\left(1+2 u-u^{2}\right) \frac{f\left(x_{n}\right)}{f^{\prime}\left(x_{n}\right)} \\
x_{n+1}=z_{n}-m(1+u)(1+4 v) v \frac{f\left(x_{n}\right)}{f^{\prime}\left(x_{n}\right)}-m(u+w) v \frac{1+6 u}{1+6 u+6 u^{2}} \frac{f\left(x_{n}\right)}{f^{\prime}\left(x_{n}\right)}
\end{array}\right.
$$

Case 2. Let us describe the following weight functions that satisfy the conditions of Theorem 2.1:

$$
G(u)=\frac{1+6 u}{1+6 u+6 u^{2}} \text { and } H(v)=\frac{1}{1-4 v} .
$$

Then, the eighth order iterative scheme is

$$
\left\{\begin{array}{l}
y_{n}=x_{n}-m \frac{f\left(x_{n}\right)}{f^{\prime}\left(x_{n}\right)} \\
z_{n}=y_{n}-m u\left(1+2 u-u^{2}\right) \frac{f\left(x_{n}\right)}{f^{\prime}\left(x_{n}\right)} \\
x_{n+1}=z_{n}-m \frac{1+u}{1-4 v} v \frac{f\left(x_{n}\right)}{f^{\prime}\left(x_{n}\right)}-m(u+w) v \frac{1+6 u}{1+6 u+6 u^{2}} \frac{f\left(x_{n}\right)}{f^{\prime}\left(x_{n}\right)}
\end{array}\right.
$$

Case 3. Next, the following weight functions from the conditions of Theorem 2.1 are selected:

$$
G(u)=\frac{1+6 u}{1+6 u+6 u^{2}} \text { and } H(v)=\frac{1+2 v}{1-2 v} \text {. }
$$

For these functions, the corresponding eighth order method is

$$
\left\{\begin{array}{l}
y_{n}=x_{n}-m \frac{f\left(x_{n}\right)}{f^{\prime}\left(x_{n}\right)} \\
z_{n}=y_{n}-m u\left(1+2 u-u^{2}\right) \frac{f\left(x_{n}\right)}{f^{\prime}\left(x_{n}\right)} \\
x_{n+1}=z_{n}-m \frac{(1+u)(1+2 v)}{1-2 v} v \frac{f\left(x_{n}\right)}{f^{\prime}\left(x_{n}\right)}-m(u+w) v \frac{1+6 u}{1+6 u+6 u^{2}} \frac{f\left(x_{n}\right)}{f^{\prime}\left(x_{n}\right)}
\end{array}\right.
$$




\section{Numerical Results}

This section is dedicated to test the efficiency and convergence of the proposed class. To do this, we consider the special cases of the proposed class, namely methods (25)-(27), denoted by NM1, $\mathrm{NM} 2$, and NM3, respectively. A total number of four test problems are selected for numerical testing. In addition, we want to compare our methods with other existing robust schemes of eighth order for multiple zeros given by Behl et al. [27,31] and Zafar et al. [28]. In this regard, we consider method (2) for $a_{1}=1, a_{2}=1$ by Behl et al. [27], two special cases of method (6) by Behl et al. [31] and two special cases method (7) (for $A_{2}=1, P_{0}=1$ ) by Zafar et al. [28], and denote them by BM1, BM2, BM3, FM1 and FM2, respectively.

Various problems considered for numerical testing are shown in Table 1. Calculations are performed in the Mathematica software using multiple-precision arithmetic. The computed numerical values shown in Tables 2-5 include: (i) number of iterations $(n)$ that are required to find the solution with stopping criterion $\left|x_{n+1}-x_{n}\right|+\left|f\left(x_{n}\right)\right|<10^{-350}$ (ii) values of the last three successive errors $\left|x_{n+1}-x_{n}\right|$, (iii) residual error $f\left(x_{n}\right)$, (iv) computational order of convergence (COC) and (v) elapsed time (CPU-time in seconds) in execution of a program, which is measured by the command "TimeUsed[ ]". The computational order of convergence (COC) is calculated by applying the formula (see [33])

$$
\mathrm{COC}=\frac{\ln \left|\left(x_{n+1}-\alpha\right) /\left(x_{n}-\alpha\right)\right|}{\ln \left|\left(x_{n}-\alpha\right) /\left(x_{n-1}-\alpha\right)\right|}
$$

Table 1. Test examples.

\begin{tabular}{|c|c|c|c|}
\hline Example & $\begin{array}{l}\text { Root } \\
(\alpha)\end{array}$ & $\begin{array}{l}\text { Multiplicity } \\
(m)\end{array}$ & $\begin{array}{l}\text { Initial Guess } \\
\left(x_{0}\right)\end{array}$ \\
\hline \multicolumn{4}{|l|}{ Example 1: Standard nonlinear function [26]: } \\
\hline $\begin{array}{l}f_{1}(x)=\left(x \log x-\sqrt{x}+x^{3}\right)^{3} \\
\text { Example 2: Standard nonlinear function [17]: }\end{array}$ & 1.000 & 3 & 1.50 \\
\hline $\begin{array}{l}f_{2}(x)=\left(x e^{x^{2}}-\sin ^{2} x+3 \cos x+5\right)^{4} \\
\text { Example 3: Standard nonlinear function [26]: }\end{array}$ & $-1.21596937 \ldots$ & 4 & -1.50 \\
\hline $\begin{array}{l}f_{3}(x)=\left(9-2 x-2 x^{4}+\cos 2 x\right)\left(5-x-x^{4}-\sin ^{2} x\right) \\
\text { Example 4: Eigen value problem [18]: }\end{array}$ & $1.29179850 \ldots$ & 2 & 1.50 \\
\hline$f_{4}(x)=x^{7}-17 x^{6}+116 x^{5}-410 x^{4}+809 x^{3}-893 x^{2}+514 x-120$ & 1 & 2 & 0.50 \\
\hline
\end{tabular}

Table 2. Comparison of performance of methods for example 1.

\begin{tabular}{|c|c|c|c|c|c|c|c|}
\hline Methods & $n$ & $\left|e_{n-2}\right|$ & $\left|e_{n-1}\right|$ & $\left|e_{n}\right|$ & $f\left(x_{n}\right)$ & $\mathrm{COC}$ & CPU-Time \\
\hline BM1 & 4 & $6.33 \times 10^{-03}$ & $7.63 \times 10^{-16}$ & $3.69 \times 10^{-119}$ & $5.90 \times 10^{-2834}$ & 7.9957 & 0.078 \\
\hline BM2 & 4 & $1.40 \times 10^{-03}$ & $1.20 \times 10^{-21}$ & $1.10 \times 10^{-062}$ & $2.79 \times 10^{-0554}$ & 2.2710 & 0.140 \\
\hline BM3 & 4 & $2.05 \times 10^{-03}$ & $4.23 \times 10^{-21}$ & $4.89 \times 10^{-061}$ & $1.81 \times 10^{-0539}$ & 2.2582 & 0.094 \\
\hline FM1 & 4 & $4.34 \times 10^{-03}$ & $4.36 \times 10^{-17}$ & $4.93 \times 10^{-129}$ & $9.54 \times 10^{-3071}$ & 7.9964 & 0.078 \\
\hline FM2 & 4 & $4.24 \times 10^{-03}$ & $3.64 \times 10^{-17}$ & $1.15 \times 10^{-129}$ & $6.83 \times 10^{-3086}$ & 7.9965 & 0.078 \\
\hline NM1 & 4 & $4.51 \times 10^{-03}$ & $3.05 \times 10^{-17}$ & $1.40 \times 10^{-130}$ & $9.34 \times 10^{-3109}$ & 7.9969 & 0.093 \\
\hline NM2 & 4 & $3.15 \times 10^{-03}$ & $1.74 \times 10^{-18}$ & $1.60 \times 10^{-140}$ & $2.35 \times 10^{-3347}$ & 7.9980 & 0.094 \\
\hline NM2 & 4 & $3.91 \times 10^{-03}$ & $9.80 \times 10^{-18}$ & $1.62 \times 10^{-134}$ & $2.96 \times 10^{-3203}$ & 7.9974 & 0.094 \\
\hline
\end{tabular}

Table 3. Comparison of performance of methods for example 2.

\begin{tabular}{|c|c|c|c|c|c|c|c|}
\hline Methods & $n$ & $\left|e_{n-2}\right|$ & $\left|e_{n-1}\right|$ & $\left|e_{n}\right|$ & $f\left(x_{n}\right)$ & $\mathrm{COC}$ & CPU-Time \\
\hline BM1 & 4 & $8.32 \times 10^{-03}$ & $5.37 \times 10^{-14}$ & $1.68 \times 10^{-103}$ & $1.03 \times 10^{-3270}$ & 7.9947 & 0.360 \\
\hline BM2 & 4 & $4.34 \times 10^{-04}$ & $1.47 \times 10^{-09}$ & $5.79 \times 10^{-026}$ & $2.57 \times 10^{-0293}$ & 3.0000 & 0.344 \\
\hline BM3 & 4 & $2.14 \times 10^{-03}$ & $2.15 \times 10^{-19}$ & $1.80 \times 10^{-055}$ & $2.12 \times 10^{-0647}$ & 2.2550 & 0.344 \\
\hline FM1 & 4 & $5.65 \times 10^{-03}$ & $3.48 \times 10^{-15}$ & $7.80 \times 10^{-113}$ & $1.04 \times 10^{-3568}$ & 7.9947 & 0.360 \\
\hline FM2 & 4 & $5.53 \times 10^{-03}$ & $2.93 \times 10^{-15}$ & $1.98 \times 10^{-113}$ & $9.76 \times 10^{-3588}$ & 7.9948 & 0.344 \\
\hline NM1 & 4 & $5.51 \times 10^{-03}$ & $8.72 \times 10^{-16}$ & $3.53 \times 10^{-118}$ & $6.94 \times 10^{-3742}$ & 7.9968 & 0.343 \\
\hline NM2 & 4 & $2.02 \times 10^{-03}$ & $2.92 \times 10^{-19}$ & $5.64 \times 10^{-146}$ & $2.28 \times 10^{-4631}$ & 7.9990 & 0.328 \\
\hline NM2 & 4 & $4.13 \times 10^{-03}$ & $8.67 \times 10^{-17}$ & $3.37 \times 10^{-126}$ & $1.64 \times 10^{-3998}$ & 7.9977 & 0.360 \\
\hline
\end{tabular}


Table 4. Comparison of performance of methods for example 3.

\begin{tabular}{cccccccc}
\hline Methods & $\boldsymbol{n}$ & $\left|\boldsymbol{e}_{\boldsymbol{n}-\mathbf{2}}\right|$ & $\left|\boldsymbol{e}_{\boldsymbol{n}-\mathbf{1}}\right|$ & $\left|\boldsymbol{e}_{\boldsymbol{n}}\right|$ & $f\left(\boldsymbol{x}_{\boldsymbol{n}}\right)$ & COC & CPU-Time \\
\hline BM1 & 4 & $6.52 \times 10^{-05}$ & $2.95 \times 10^{-32}$ & $5.20 \times 10^{-251}$ & $4.85 \times 10^{-3999}$ & 7.9999 & 0.250 \\
BM2 & 4 & $6.81 \times 10^{-09}$ & $2.06 \times 10^{-24}$ & $5.69 \times 10^{-71}$ & $2.96 \times 10^{-418}$ & 3.0000 & 0.219 \\
BM3 & 4 & $7.63 \times 10^{-06}$ & $1.35 \times 10^{-40}$ & $1.61 \times 10^{-119}$ & $1.53 \times 10^{-709}$ & 2.2711 & 0.219 \\
FM1 & 4 & $4.88 \times 10^{-05}$ & $3.85 \times 10^{-33}$ & $5.74 \times 10^{-258}$ & $1.10 \times 10^{-4085}$ & 7.9999 & 0.187 \\
FM2 & 4 & $4.81 \times 10^{-05}$ & $3.40 \times 10^{-33}$ & $2.13 \times 10^{-258}$ & 0 & 7.9999 & 0.203 \\
NM1 & 4 & $3.59 \times 10^{-05}$ & $1.29 \times 10^{-34}$ & $3.67 \times 10^{-270}$ & 0 & 7.9999 & 0.188 \\
NM2 & 4 & $2.73 \times 10^{-05}$ & $1.44 \times 10^{-35}$ & $8.58 \times 10^{-278}$ & 0 & 7.9999 & 0.203 \\
NM2 & 4 & $3.17 \times 10^{-05}$ & $4.79 \times 10^{-35}$ & $1.31 \times 10^{-273}$ & 0 & 7.9999 & 0.204 \\
\hline
\end{tabular}

Table 5. Comparison of performance of methods for example 4 .

\begin{tabular}{cccccccc}
\hline Methods & $\boldsymbol{n}$ & $\left|\boldsymbol{e}_{\boldsymbol{n}-\mathbf{2}}\right|$ & $\left|\boldsymbol{e}_{\boldsymbol{n}-\mathbf{1}}\right|$ & $\left|\boldsymbol{e}_{\boldsymbol{n}}\right|$ & $f\left(\boldsymbol{x}_{\boldsymbol{n}}\right)$ & COC & CPU-Time \\
\hline BM1 & 4 & $1.27 \times 10^{-03}$ & $1.47 \times 10^{-22}$ & $4.85 \times 10^{-147}$ & $7.90 \times 10^{-4155}$ & 7.9995 & 0.078 \\
BM2 & 4 & $2.13 \times 10^{-04}$ & $1.91 \times 10^{-29}$ & $2.02 \times 10^{-086}$ & $3.25 \times 10^{-0769}$ & 2.2747 & 0.172 \\
BM3 & 4 & $3.30 \times 10^{-04}$ & $5.27 \times 10^{-29}$ & $4.24 \times 10^{-085}$ & $2.55 \times 10^{-0757}$ & 2.2621 & 0.157 \\
FM1 & 4 & $8.52 \times 10^{-04}$ & $6.89 \times 10^{-24}$ & $1.28 \times 10^{-184}$ & $1.48 \times 10^{-4408}$ & 7.9996 & 0.109 \\
FM2 & 4 & $8.35 \times 10^{-04}$ & $5.89 \times 10^{-24}$ & $3.65 \times 10^{-185}$ & $1.23 \times 10^{-4421}$ & 7.9996 & 0.093 \\
NM1 & 4 & $8.50 \times 10^{-04}$ & $3.78 \times 10^{-24}$ & $5.84 \times 10^{-187}$ & $1.59 \times 10^{-4465}$ & 7.9997 & 0.109 \\
NM2 & 4 & $6.65 \times 10^{-04}$ & $5.32 \times 10^{-25}$ & $8.92 \times 10^{-194}$ & $4.20 \times 10^{-4629}$ & 7.9997 & 0.109 \\
NM2 & 4 & $7.63 \times 10^{-04}$ & $1.60 \times 10^{-24}$ & $5.87 \times 10^{-190}$ & $1.81 \times 10^{-4537}$ & 7.9997 & 0.125 \\
\hline
\end{tabular}

From the above tables, we observe that the accuracy is increasing in the values of successive approximations, which points to the good convergence of the methods. The present methods also show consistent convergence behavior as compared to the existing methods. At the time when stopping criterion $\left|x_{n+1}-x_{n}\right|+\left|f\left(x_{n}\right)\right|<10^{-350}$ is attained, the value ' 0 ' for $\left|x_{n+1}-x_{n}\right|$ is displayed. Computational order of convergence shown in the penultimate column of each table overwhelmingly supports the theoretical convergence of order eight. The CPU-time values in the last column of each table show that the new methods utilize less execution time than the time used by existing methods, which confirms the effectiveness of the proposed techniques. The main motive to apply these methods on different types of nonlinear equations is to illustrate the exactness of the obtained approximate solution and the convergence to the solution. Similar numerical tests, performed on a variety of numerical problems of different kinds, ensured the above remarks to a large extent.

\section{Basins of Attraction}

We aim to present the complex dynamical nature of new methods based on the geometrical tool, namely basins of attraction of the multiple zeros of a polynomial $P(z)$. Study of basins of attraction provides an important information about the stability and convergence of numerical methods. Initially, this idea was floated by Vrscay and Gilbert [34]. In recent times, many authors have used this idea in their work, see, for example $[35,36]$ and references given there. The basic definitions related to dynamical concepts of rational function associated with iterative methods can be found in [34].

To view the geometry in complex plane, we assess the attraction basins of the roots by applying the methods on some polynomials (see Table 6). The basins of attraction assessed are shown in Figures 1-3 for the considered polynomials. To plot basins we use rectangles $R \in \mathbb{C}$ of size $[-2,2] \times[-2,2]$ and $[-3,3] \times[-3,3]$, and assign different colors to the basins. Black color is assigned to the points for which the method is divergent. 
Table 6. Comparison of performance based on basins of attraction of methods.

\begin{tabular}{ccccccc}
\hline S. No. & Test Problems & $m$ & Roots & Color of Fractal & Best Performer & Poor Performer \\
\hline 1 & $P_{1}(z)=\left(z^{2}-1\right)^{3}$ & 3 & -1 & green & BM1, NM2, NM3, & FM1, FM2 \\
& & & 1 & red & BM2, BM3, NM1 & FM1, FM2 \\
2 & $P_{2}(z)=\left(z^{3}-z\right)^{3}$ & 3 & -1 & red & BM3, BM2, NM2 & FM1, \\
& & & 0 & green & NM1, BM1 & \\
& & & 1 & blue & BM3, NM2, BM2 & FM1, FM2 \\
3 & $P_{3}(z)=z^{4}-6 z^{2}+8$ & 1 & -2 & red & NM3, NM1, BM1 & \\
& & & -1.414 & green & & \\
& & & 1.414 & yellow & & \\
& & & & blue & &
\end{tabular}

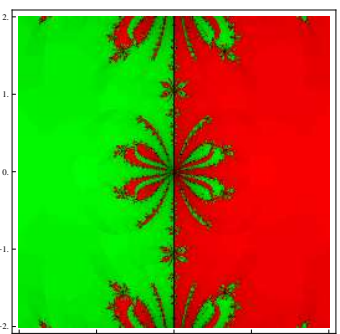

BM1.

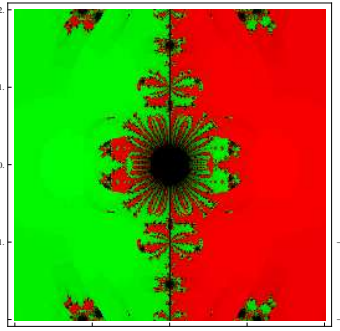

FM2.

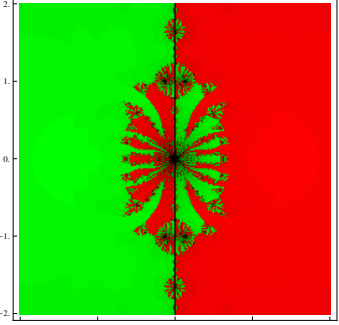

BM2

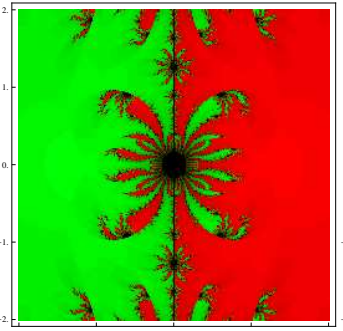

NM1.

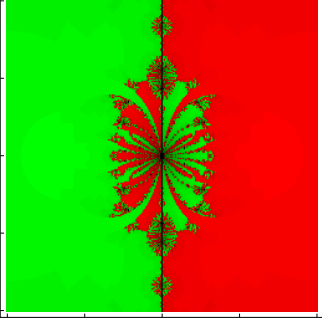

BM3

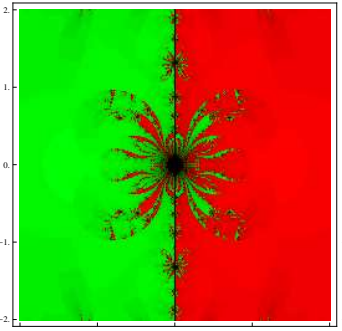

NM2.

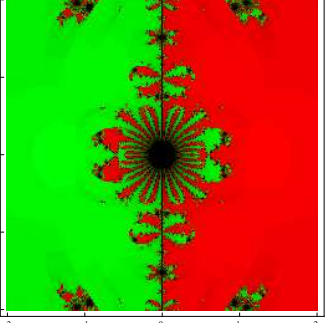

FM1.

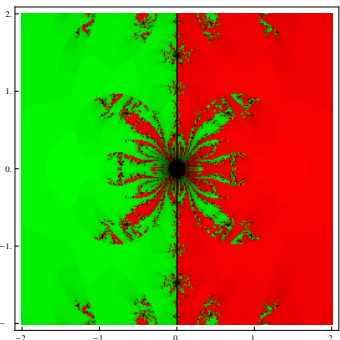

NM3.

Figure 1. Basins of attraction of $B M 1, B M 2, B M 3, F M 1, F M 2, N M 1, N M 2, N M 3$ for polynomial $P_{1}(z)$.

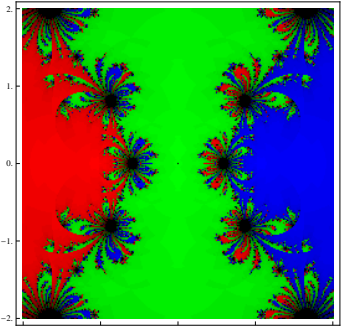

BM1.

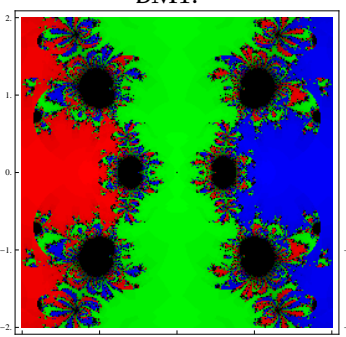

FM2.

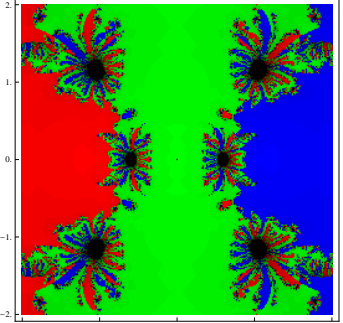

BM2.

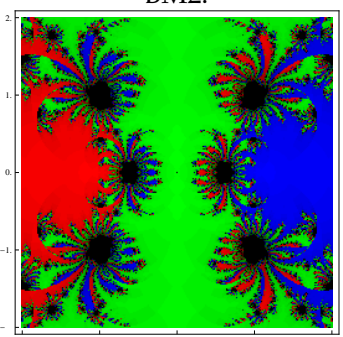

NM1.

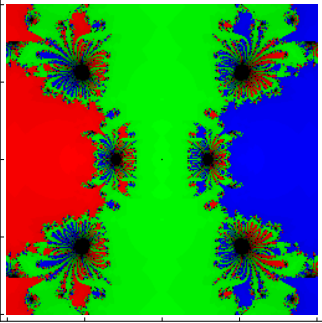

BM3.

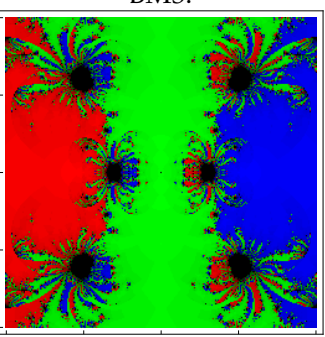

NM2.

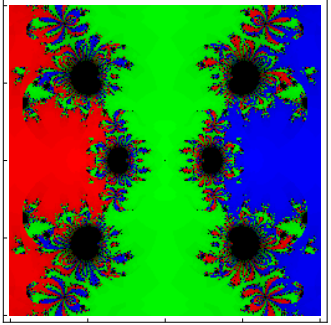

FM1.

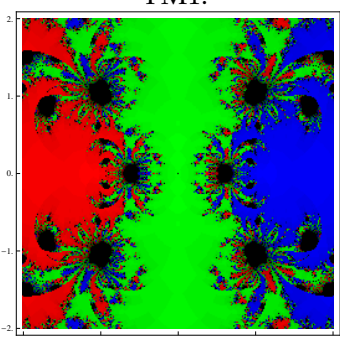

NM3.

Figure 2. Basins of attraction of $B M 1, B M 2, B M 3, F M 1, F M 2, N M 1, N M 2, N M 3$ for polynomial $P_{2}(z)$. 


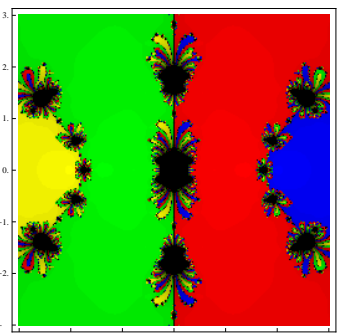

BM1.

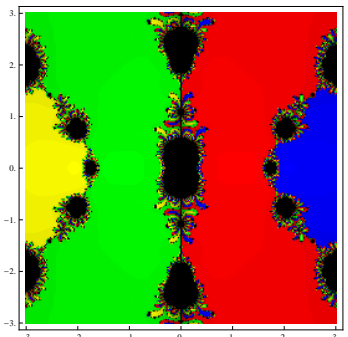

BM2.

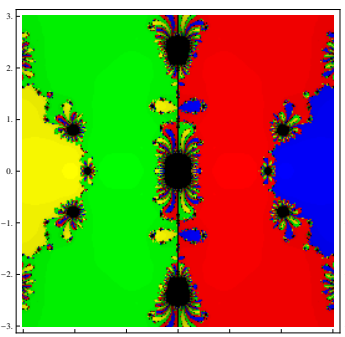

BM2.

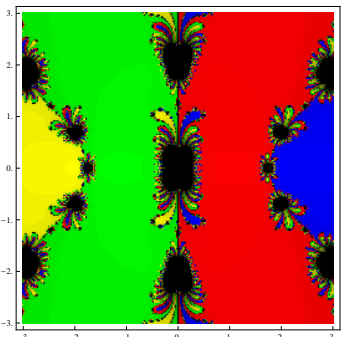

NM1.

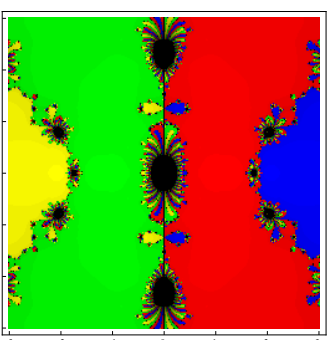

BM3.

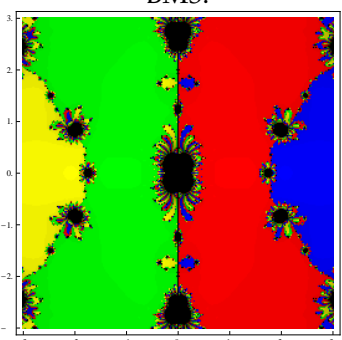

NM2.

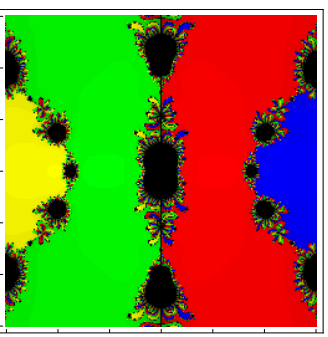

FM1.

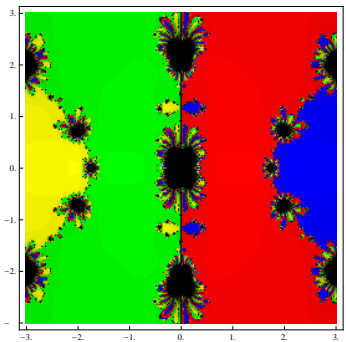

NM3.

Figure 3. Basins of attraction of $B M 1, B M 2, B M 3, F M 1, F M 2, N M 1, N M 2, N M 3$ for polynomial $P_{3}(z)$.

From these graphics, one can easily check the behavior and stability of any iterative procedure. If an initial guess $z_{0}$ is chosen in a region where different basins meet each other, it is difficult to guess which zero is going to be attained by the method that starts in $z_{0}$. So, the selection of $z_{0}$ in such a region is not preferable. Both the black zone (divergent zone) and the zones with different colors are not suitable to consider the initial guess $z_{0}$ when we want to acquire a unique root. The most adorable pictures can be seen along the boundaries between the basins of attraction. These boundaries have fractal-like pictures and belong to the cases where the method is more demanding with choice of initial point. At such regions, the dynamic behavior of the initial guess is more unpredictable.

\section{Conclusions}

In this research article, we have developed a class of optimal eighth order methods for locating multiple roots of nonlinear equations with known multiplicity. The analysis of the order of convergence has been discussed, that proves the order eighth under well-known assumptions regarding the nonlinear function whose zeros we are looking for. Some particular cases have been presented and their performance has been compared with well-known methods available in literature. The robustness of new algorithms can be judged by the fact that the accuracy in the successive approximations to the solution is much better compared to the accuracy of existing ones. Moreover, the used CPU time in execution of program is less than that of the CPU time taken by the existing techniques in majority of the cases. These conclusions have also been verified by similar numerical testing on many other different problems.

Author Contributions: Methodology, D.K. and S.K.; Formal analysis, J.R.S.; Investigation, J.R.S.; Data Curation, J.R.S.; Conceptualization, M.d.; Writing-review \& editing, D.K. and S.K. All authors have read and agreed to the published version of the manuscript.

Funding: This research received no external funding.

Conflicts of Interest: The authors declare no conflict of interest.

\section{References}

1. Argyros, I.K. Convergence and Applications of Newton-Type Iterations; Springer: New York, NY, USA, 2008.

2. Constantinides, A.; Mostoufi, N. Numerical Methods for Chemical Engineers with MATLAB Applications; Prentice Hall PTR: Upper Saddle River, NJ, USA, 1999. 
3. Kung, H.T.; Traub, J.F. Optimal order of one-point and multipoint iteration. J. Assoc. Comput. Mach. 1974, 21, 643-651. [CrossRef]

4. Ostrowski, A.M. Solution of Equations and Systems of Equations; Academic Press: New York, NY, USA, 1966.

5. Traub, J.F. Iterative Methods for the Solution of Equations; Chelsea Publishing Company: New York, NY, USA, 1982.

6. Schröder, E. Über unendlich viele Algorithmen zur Auflösung der Gleichungen. Math. Ann. 1870, 2, 317-365. [CrossRef]

7. Hansen, E.; Patrick, M. A family of root finding methods. Numer. Math. 1977, 27, 257-269. [CrossRef]

8. Victory, H.D.; Neta, B. A higher order method for multiple zeros of nonlinear functions. Int. J. Comput. Math. 1983, 12, 329-335. [CrossRef]

9. Osada, N. An optimal multiple root-finding method of order three. J. Comput. Appl. Math. 1994, 51, 131-133. [CrossRef]

10. Li, S.; Liao, X.; Cheng, L. A new fourth-order iterative method for finding multiple roots of nonlinear equations. Appl. Math. Comput. 2009, 215, 1288-1292.

11. Li, S.G.; Cheng, L.Z.; Neta, B. Some fourth-order nonlinear solvers with closed formulae for multiple roots. Comput Math. Appl. 2010, 59, 126-135. [CrossRef]

12. Sharma, J.R.; Sharma, R. Modified Jarratt method for computing multiple roots. Appl. Math. Comput. 2010, 217, 878-881. [CrossRef]

13. Neta, B. Extension of Murakamis high-order nonlinear solver to multiple roots. Int. J. Comput. Math. 2010, 87, 1023-1031. [CrossRef]

14. Zhou, X.; Chen, X.; Song, Y. Constructing higher-order methods for obtaining the multiple roots of nonlinear equations. J. Comput. Math. Appl. 2011, 235, 4199-4206. [CrossRef]

15. Sharifi, M.; Babajee, D.K.R.; Soleymani, F. Finding the solution of nonlinear equations by a class of optimal methods. Comput. Math. Appl. 2012, 63, 764-774. [CrossRef]

16. Soleymani, F.; Babajee, D.K.R.; Lotfi, T. On a numerical technique for finding multiple zeros and its dynamics. J. Egypt. Math. Soc. 2013, 21, 346-353. [CrossRef]

17. Geum, Y.H.; Kim, Y.I.; Neta, B. A class of two-point sixth-order multiple-zero finders of modified double-Newton type and their dynamics. Appl. Math. Comput. 2015, 270, 387-400. [CrossRef]

18. Kansal, M.; Kanwar, V.; Bhatia, S. On some optimal multiple root-finding methods and their dynamics. Appl. Appl. Math. 2015, 10,349-367.

19. Soleymani, F.; Babajee, D.K.R. Computing multiple zeros using a class of quartically convergent methods. Alex. Eng. J. 2013, 52, 531-541. [CrossRef]

20. Liu, B.; Zhou, X. A new family of fourth-order methods for multiple roots of nonlinear equations. Nonlinear Anal. Model. Cont. 2013, 18, 143-152. [CrossRef]

21. Zhou, X.; Chen, X.; Song, Y. Families of third and fourth order methods for multiple roots of nonlinear equations. Appl. Math. Comput. 2013, 219, 6030-6038. [CrossRef]

22. Thukral, R. A new family of fourth-order iterative methods for solving nonlinear equations with multiple roots. J. Numer. Math. Stoch. 2014, 6, 37-44.

23. Behl, R.; Cordero, A.; Motsa, S.S.; Torregrosa, J.R. On developing fourth-order optimal families of methods for multiple roots and their dynamics. Appl. Math. Comput. 2015, 265, 520-532. [CrossRef]

24. Hueso, J.L.; Martz, E.; Teruel, C. Determination of multiple roots of nonlinear equations and applications. J. Math. Chem. 2015, 53, 880-892. [CrossRef]

25. Behl, R.; Cordero, A.; Motsa, S.S.; Torregrosa, J.R.; Kanwar, V. An optimal fourth-order family of methods for multiple roots and its dynamics. Numer. Algorithms 2016, 71, 775-796. [CrossRef]

26. Geum, Y.H.; Kim, Y.I.; Neta, B. A sixth-order family of three-point modified Newton-like multiple-root finders and the dynamics behind their extraneous fixed points. Appl. Math. Comput. 2016, 283, 120-140. [CrossRef]

27. Behl, R.; Cordero, A.; Motsa, S.S.; Torregrosa, J.R. An eighth-order family of optimal multiple root finders and its dynamics. Numer. Algorithms 2018, 77, 1249-1272. [CrossRef]

28. Zafar, F.; Cordero, A.; Rana, Q.; Torregrosa, J.R. Optimal iterative methods for finding multiple roots of nonlinear equations using free parameters. J. Math. Chem. 2018, 56, 1884-1901. [CrossRef] 
29. Geum, Y.H.; Kim, Y.I.; Neta, B. Constructing a family of optimal eighth-order modified Newton-type multiple-zero finders along with the dynamics behind their purely imaginary extraneous fixed points. J. Comput. Appl. Math. 2018, 333, 131-156. [CrossRef]

30. Behl, R.; Zafar, F.; Alshomrani, A.S.; Junjua, M.; Yasmin, N. An optimal eighth-order scheme for multiple zeros of univariate function. Int. J. Comput. Math. 2018, 15, 14. [CrossRef]

31. Behl, R.; Alshomrani, A.S.; Motsa, S.S. An optimal scheme for multiple roots of nonlinear equations with eighth-order convergence. J. Math. Chem. 2018, 56, 2069-2084. [CrossRef]

32. Zafar, F.; Cordero, A.; Torregrosa, J.R. An efficient family of optimal eighth-order multiple root finder. Mathematics 2018, 6, 310. [CrossRef]

33. Weerakoon, S.; Fernando, T.G.I. A variant of Newton's method with accelerated third-order convergence. Appl. Math. Lett. 2000, 13, 87-93. [CrossRef]

34. Vrscay, E.R.; Gilbert, W.J. Extraneous fixed points, basin boundaries and chaotic dynamics for Schröder and König rational iteration functions. Numer. Math. 1988, 52, 1-16. [CrossRef]

35. Varona, J.L. Graphic and numerical comparison between iterative methods. Math. Intell. 2002, 24, 37-46. [CrossRef]

36. Scott, M.; Neta, B.; Chun, C. Basin attractors for various methods. Appl. Math. Comput. 2011, 218, $2584-2599$. [CrossRef]

Publisher's Note: MDPI stays neutral with regard to jurisdictional claims in published maps and institutional affiliations.

(C) 2020 by the authors. Licensee MDPI, Basel, Switzerland. This article is an open access article distributed under the terms and conditions of the Creative Commons Attribution (CC BY) license (http:/ / creativecommons.org/licenses/by/4.0/). 